\title{
Amorphous and ordered organosilicas functionalized with amine groups as sorbents of platinum (II) ions
}

\author{
Mariusz Barczak • Ryszard Dobrowolski • \\ Joanna Dobrzyńska $\cdot$ Emil Zięba $\cdot$ Andrzej Dąbrowski
}

Received: 12 November 2012/ Accepted: 5 February 2013/Published online: 20 February 2013

(C) The Author(s) 2013. This article is published with open access at Springerlink.com

\begin{abstract}
Two groups of amine-functionalized organosilicas have been synthesized: amorphous polysiloxane xerogels (APX) and ordered mesoporous organosilicas (OMO) by co-condensation of tetraethoxysilane and appropriate alkoxysilanes: aminopropyltriethoxysilane and $N$-[3-(trimethoxysilyl)propyl]ethylenediamine. The obtained materials were characterized by sorption measurements, $\mathrm{X}$-ray diffractometry, elemental analysis, transmission electron microscopy, and scanning electron microscopy. The OMO samples have well developed porous structure-the values of specific surface area are in the range $740-840 \mathrm{~m}^{2} /$ g. While the APX samples are less porous having the corresponding values in the range $280-520 \mathrm{~m}^{2} / \mathrm{g}$. The sizes of the ordered mesopores of OMO are in the range $5.9-6.5 \mathrm{~nm}$ while for the APX they are 2.9-12.1 nm indicating structural differences between both groups of the samples. All samples were tested as the sorbents of Pt(II) ions. The influence of various parameters such as $\mathrm{pH}$, contact time, equilibrium concentration on $\mathrm{Pt}(\mathrm{II})$ adsorption ability onto prepared adsorbents was studied in detail. Additionally, the effect of chloride concentration on Pt(II) adsorption was investigated. The values of static sorption capacities were in the range of 32-102 $\mathrm{mg}_{\mathrm{Pt}(\mathrm{II}) / \mathrm{g}}$ and $20-139 \mathrm{mg}_{\mathrm{Pt}(\mathrm{II}) / \mathrm{g}}$ for OMO and APX series, respectively.
\end{abstract}

\footnotetext{
M. Barczak $(\bowtie) \cdot$ R. Dobrowolski · J. Dobrzyńska ·

A. Dąbrowski

Faculty of Chemistry, Maria Curie-Sklodowska University,

Maria Curie-Sklodowska Sq. 3, 20-031 Lublin, Poland

e-mail: mbarczak@umcs.pl

E. Zięba

SEM Laboratory, Department of Zoology and Ecology, Catholic University of Lublin, Al. Kraśnicka 102, 20-718 Lublin, Poland
}

Keywords Sol-gel $\cdot$ Polysiloxanes $\cdot$ Organosilicas · Functionalization · Adsorption · Platinum

\section{Introduction}

The sol-gel method offers great opportunities for designing hybrid porous materials (Brinker and Scherer 1990; Kickelbick 2007; Ferey 2008). In particular porous materials based on silica are widely exploited nowadays in many fields including adsorption, catalysis, sensors, membranes (Sakka 2005; Shea et al. 2004; Collinsona 1999). The wide potentialities of the sol-gel method were demonstrated at the end of the past century by the synthesis of silicas functionalized with the groups capable of complexation (Avnir et al. 1998; Feng et al. 1997). The functional surface layer is a precise tool for affecting the properties of xerogels, for example, sorption characteristics, due to the possibilities of varying both the nature of the functional groups in such a layer and the porous structure.

Functionalized amorphous polysiloxane xerogels (APX) are a class of hybrid organic-inorganic materials, usually obtained by hydrolysis and polycondensation reactions of tetraethoxysilane (TEOS) and appropriate organosilicas monomers (Slinyakova 1988; El-Nahhala and El-Ashgarb 2007). The sol-gel method provides here a possibility to design —on a molecular level-the considered materials keeping control over their chemical and physical properties, including structure-adsorption characteristics (Loy et al. 1996; Dąbrowski et al. 2007). Particularly, this method allows for obtaining micro- and mesoporous materials with high specific surface areas. Thus, APX were tested as effective sorbents for the preconcentration, separation and extraction of heavy metal ions under static and dynamic conditions, as well as catalysts for different reactions 
(Cermak et al. 1996; El-Nahhal and El-Ashgar 2007). Modified polysiloxanes have found a wide application in gas chromatography (El-Nasser and Parish 1999) and as active phases of potentiometric sensors (Colilla et al. 2005).

The first family of ordered mesoporous silicas (OMSs) materials called M41S was discovered in 1990 (Yanagisawa et al. 1990; Kresge et al. 1992; Beck et al. 1992); this was followed by discovery of hexagonally arranged and highly ordered SBA-15 materials in 1998 (Zhao et al. 1998a, b; Goltner et al. 1998). OMSs possess many advantages such as easy one-step synthesis, tuneable pores size, thick pore walls, high specific surface area, and good textural properties. Possibility of functionalization of the OMSs makes them very attractive candidates for sensing devices, environmental applications and particularly, for catalytic and adsorption processes (Taguchi and Schüth 2005; Trewyn et al. 2007; Hartmann 2005). Particularly, the amine-functionalized SBA-15 materials have found numerous applications in adsorption of many species including biomolecules and pharmaceuticals (Hartmann 2005; Humphrey et al. 2001; Bui and Choi 2009), as well as heavy metal ions (Liu et al. 2000; Kang et al. 2004; Olkhovyk and Jaroniec 2005; Aguado et al. 2009; Barczak et al. 2010). However, there is still little information about application of these materials for removal of noble metals (Kang et al. 2004).

Platinum is one of the most relevant noble metals present in the biosphere, and the recovery of this metal from waters became a very important task, due to its limited world reserves, high cost and wide use in different industries: electrical, petrochemistry, medicine, jewellery, etc. (Jermakowicz-Bartkowiak et al. 2005). On the other hand, there are many problems related to the determination of low concentrations of platinum in the environmental samples where preconcentration step is usually required (Bencs et al. 2003; Zolotov and Kuzmin 1990). The functionalized organosilicas, due to their favoured adsorption characteristics, can be potentially employed for uptake/sorption/recovery of platinum.

In this work the amine-functionalized APX and OMO were synthesized, characterized and compared as sorbents for $\mathrm{Pt}(\mathrm{II})$ adsorption. In order to evaluate the possibility of application of synthesized samples for separation and enrichment of $\mathrm{Pt}(\mathrm{II})$ from aqueous solutions, the parameters affecting the sorption properties were considered (i.e. $\mathrm{pH}$, contact time, chloride ions concentration and equilibrium $\mathrm{Pt}(\mathrm{II})$ ion concentration).

\section{Experimental}

\subsection{Reagents}

The following compounds were used: tetraethoxysilane (TEOS, $99 \%$, ABCR), 3-aminopropyltriethoxysilane
(APTS, $98 \%, \quad$ ABCR), N-[3-(trimethoxysilyl)propyl]ethylenediamine (TMPD, $97 \%, \mathrm{ABCR}), \mathrm{NH}_{4} \mathrm{~F}(98 \%$, $\mathrm{POCH}), \mathrm{HCl}(36 \%, \mathrm{POCH}), \mathrm{NaOH}(\mathrm{POCH})$, ethanol (EtOH, 99.8\%, POCH), Pluronic P123 (P123, SigmaAldrich), potassium tetrachloroplatinate(II) (>99.9\%, Sigma-Aldrich), sodium chloride (POCH), thiourea $(\mathrm{POCH}), \mathrm{NaCl}(\mathrm{POCH}), \mathrm{KNO}_{3}(\mathrm{POCH})$. All chemicals were used as received, without further purification.

\subsection{Synthesis of OMO samples M1-M4}

The synthesis of these samples was described by us before (Barczak et al. 2009, 2010). In the model synthesis, $2 \mathrm{~g}$ of $\mathrm{P} 123$ was dissolved in $60 \mathrm{~mL}$ of $2 \mathrm{~mol} / \mathrm{L} \mathrm{HCl}$ and $11 \mathrm{~mL}$ of deionized water under vigorous stirring at $40{ }^{\circ} \mathrm{C}$. After $8 \mathrm{~h}$ of stirring TEOS was added dropwise to this solution. After $15 \mathrm{~min}$ the APTS (samples $M 1$ and M2) or TMPD (samples $M 3$ and $M 4$ ) was added dropwise. The resulting mixture was stirred at $40{ }^{\circ} \mathrm{C}$ for $24 \mathrm{~h}$ and aged at $100{ }^{\circ} \mathrm{C}$ for next $48 \mathrm{~h}$. The white solid was washed with deionized water, filtered and dried at $70{ }^{\circ} \mathrm{C}$. The template was removed by three-time extraction with the acidified $\mathrm{EtOH}$ at $70{ }^{\circ} \mathrm{C}$. The numeration of the samples was as follows: $M O($ TEOS $=20 \mathrm{mmol}=20 / 0), M I($ TEOS/APTS $=19 / 1)$, M2 $($ TEOS/APTS $=18 / 2), M 3 \quad($ TEOS $/ \mathrm{TMPD}=19 / 1)$, M4 (TEOS/TMPD $=18 / 2)$.

\subsection{Synthesis of APX samples X1-X4}

The syntheses of these samples were similar to those described previously (Zub et al. 2010; Barczak and Borowski 2009). In the model synthesis, a solution of $\mathrm{NH}_{4} \mathrm{~F}$ was added to the solution of TEOS in $15 \mathrm{~mL}$ of EtOH. After 5 min the solution of APTS (samples $X 1$ and $X 2$ ) or TMPD (samples $X 3$ and $X 4$ ) in $15 \mathrm{~mL}$ of EtOH was added to this mixture. Opalescating gels were formed in a few minutes. After two days, the gel was pounded and dried in vacuum at $30 / 65 / 105{ }^{\circ} \mathrm{C}-2 \mathrm{~h}$ at each temperature.

\subsection{Instrumental characterization}

The CHN elemental analysis was carried out using the Perkin Elmer CHN 2400 analyzer. Powder X-ray diffraction (XRD) patterns were recorded using a Seifert RTG DRON-3 diffractometer ( $\mathrm{CuK} \alpha$ radiation) with $0.02^{\circ}$ size step and $10 \mathrm{~s}$ time step covering the range of $0.5^{\circ}<2 \theta<5.0^{\circ}$ at room temperature. The SEM analysis of randomly selected parts of the surface was performed by means of LEO SEM 1430 VP microscope. The accelerating voltage was set to $20 \mathrm{keV}$, and the beam current to $80 \mathrm{~mA}$.

Nitrogen adsorption/desorption isotherms were measured at $-196{ }^{\circ} \mathrm{C}$ using an ASAP-2405 $\mathrm{N}$ analyzer. All samples were degassed at $110{ }^{\circ} \mathrm{C}$ in vacuum prior to 
measurements. BET specific surface areas $\left(\mathrm{S}_{\mathrm{BET}}\right)$ were evaluated in the range of relative pressures $\mathrm{p} / \mathrm{p}_{\mathrm{o}}$ of 0.05-0.25 (Brunauer et al. 1938). Total pore volumes $\left(\mathrm{V}_{\mathrm{p}}\right)$ were calculated by converting the amount adsorbed at $\mathrm{p} / \mathrm{p}_{\mathrm{o}}$ $\sim 0.99$ to the volume of liquid adsorbate. Average pore sizes $\left(\mathrm{d}_{\mathrm{BJH}}\right)$ were estimated using the BJH method (Barrett et al. 1951), while pore size distributions (PSD) from the desorption branches of isotherms using the same approach.

XPS spectra were obtained using a Multi-chamber analytical system (Prevac, Poland) with monochromated $\mathrm{K} \alpha$-Al radiation (1486.6 eV) (Gammadata Scienta, Sweden) and an X-ray power of $450 \mathrm{~W}$. The binding energy (BE) scale was referenced against $\mathrm{C} 1 \mathrm{~s}=284.7 \mathrm{eV}$ line. The vacuum in the analysis chamber was $8 \times 10^{-9} \mathrm{~Pa}$. The high-resolution scans were performed over the 69-81, 99-110, 192-206, 282-294, 395-407, 527-538 eV ranges for $\mathrm{Pt} 4 \mathrm{f}, \mathrm{Si} 2 \mathrm{p}, \mathrm{Cl} 2 \mathrm{p}, \mathrm{C} 1 \mathrm{~s}, \mathrm{~N} 1 \mathrm{~s}$ and $\mathrm{O} 1 \mathrm{~s}$ spectra, respectively.

\subsection{Adsorption measurements}

The batch mode was used to examine the sorption of $\mathrm{Pt}(\mathrm{II})$ ions. In every experiment, $50 \mathrm{mg}$ of adsorbent and $50 \mathrm{~mL}$ of platinum solution were stirred at $25^{\circ} \mathrm{C}$. After the adsorption equilibrium had been attained, the solution was separated from the sorbent by centrifugation. The equilibrium adsorption quantity was calculated according to the following formula:

$a=\frac{\left(c_{i}-c\right) \cdot V}{m}$

where $c_{i}$ is the initial $\mathrm{Pt}(\mathrm{II})$ concentration (in $\mathrm{mg} / \mathrm{L}$ ), $c$ is the equilibrium $\mathrm{Pt}(\mathrm{II})$ concentration (in $\mathrm{mg} / \mathrm{L}$ ), $V$ is the volume of the solution (in L) and $m$ is the mass of the adsorbent (in $\mathrm{g}$ ). Measurements were carried out using the atomic absorption spectrometer AAS-3 (Carl Zeiss) equipped with a deuterium-lamp background corrector, an EA-3 electrothermal atomizer, and an MPE autosampler. Measurements were performed using the Pt hollow cathode lamp (Varian) at a wavelength of $265.9 \mathrm{~nm} ; 0.2 \mathrm{~nm}$ slit width was used. The time-temperature program applied in $\mathrm{Pt}(\mathrm{II})$ determination was as follows: drying: $120{ }^{\circ} \mathrm{C}$ for $10 \mathrm{~s}$; pyrolysis: $1200{ }^{\circ} \mathrm{C}$ for $5 \mathrm{~s}$; atomization: $2600{ }^{\circ} \mathrm{C}$ for $2 \mathrm{~s}$. Pure argon was used as the inert gas with a flow rate of $280 \mathrm{~mL} / \mathrm{min}$ except the atomization stage.

\section{Results}

3.1 Synthesis, characterization and efficiency of functionalization

The scheme of the co-condensation of TEOS with functionalized silanes (APTS or TMPD) is presented in Fig. 1. The molar ratios of TEOS/APTS and TEOS/TMPD in the reacting systems were 19:1 and 18:2. Such ratios were selected to achieve the high content of functional groups in the final materials and, in addition, to avoid fast gelation, which is often observed (even in the case of OMO samples) when the relative amount of amine-functionalized silane increases (Dạbrowski et al. 2005). All synthesized samples (OMO and AFX) are non-swelling in common non-aqueous solvents.

The content of nitrogen (and thus amine groups) in the synthesized samples is presented in Table 1. For all APX samples the nitrogen content is around $70-80 \%$ of the theoretical values (calculated from the initial amounts of co-condensing alkoxysilanes). In the case of OMO samples, the nitrogen content is around 50-60\% of the values estimated on the basis of the initial molar composition, indicating less effective incorporation of amine groups than in the case of APX. Apparently, a part of the amine groups is lost during ageing, drying and extraction steps. It can be also seen that in the case of OMO samples there is higher carbon content due to incomplete removal of the template. This is confirmed by the FTIR spectra (not given here) where a group of absorption bands in the region of 2860-3030 $\mathrm{cm}^{-1}$, is attributed to the stretching modes of $\mathrm{CH}_{2}$ groups of poly(oxyethylene) and poly(oxypropylene) blocks of Pluronic P123 (Barczak et al. 2010).

The nitrogen adsorption-desorption isotherms of the APX and OMO samples are shown in Fig. 2. All the OMO samples exhibit the type IV isotherms according to the IUPAC classification (Rouquerol et al. 1999). The most striking feature is the presence of sharp capillary

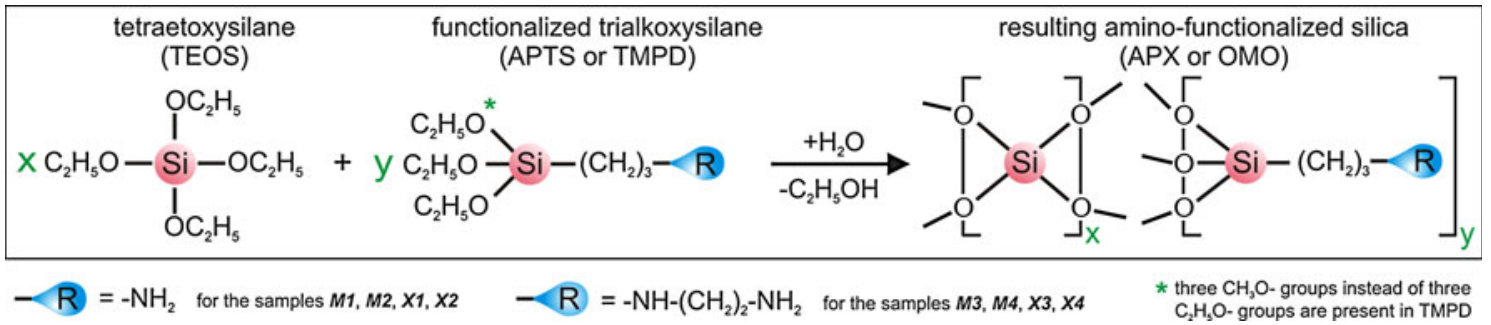

Fig. 1 Scheme of the co-condensation of TEOS with APTS and TMPD 
Table 1 Structure-adsorption characteristics of the obtained APX and OMO samples

\begin{tabular}{|c|c|c|c|c|c|c|c|}
\hline Sample & $\begin{array}{l}\text { Molar } \\
\text { composition } \\
(\mathrm{mmol})\end{array}$ & $\begin{array}{l}\mathrm{S}_{\mathrm{BET}}^{\mathrm{a}} \\
\left(\mathrm{m}^{2} / \mathrm{g}\right)\end{array}$ & $\begin{array}{l}\mathrm{V}_{\mathrm{p}}^{\mathrm{b}} \\
\left(\mathrm{cm}^{3}\right)\end{array}$ & $\begin{array}{l}\mathrm{d}_{\mathrm{BJH}}^{\mathrm{c}} \\
(\mathrm{nm})\end{array}$ & $\begin{array}{l}\% \mathrm{~N} \text { (elemental } \\
\text { analysis) }\end{array}$ & $\begin{array}{l}\text { Measured content of amino } \\
\text { groups }(\mathrm{mmol} / \mathrm{g})\end{array}$ & $\begin{array}{l}\text { Theoretical content of amino } \\
\text { groups }(\mathrm{mmol} / \mathrm{g})\end{array}$ \\
\hline MO & TEOS $20: 0$ & 789 & 1.29 & 5.9 & 0.00 & 0.00 & 0.00 \\
\hline$M 1$ & $\begin{array}{l}\text { TEOS:APTS } 19: \\
1\end{array}$ & 804 & 1.30 & 6.8 & 0.77 & 0.48 & 0.80 \\
\hline$M 2$ & $\begin{array}{l}\text { TEOS: APTS } 18 \text { : } \\
2\end{array}$ & 838 & 1.43 & 6.7 & 1.22 & 0.76 & 1.54 \\
\hline$M 3$ & $\begin{array}{l}\text { TEOS:TMPD 19: } \\
1\end{array}$ & 808 & 1.36 & 6.6 & 1.21 & 0.78 & 1.55 \\
\hline M4 & $\begin{array}{l}\text { TEOS:TMPD } 18: \\
2\end{array}$ & 738 & 1.30 & 6.5 & 2.08 & 1.34 & 2.89 \\
\hline$X 0$ & TEOS $20: 0$ & 104 & 0.06 & 2.9 & 0.00 & 0.00 & 0.00 \\
\hline$X 1$ & $\begin{array}{l}\text { TEOS: APTS } 19 \text { : } \\
1\end{array}$ & 467 & 0.36 & 3.7 & 1.00 & 0.63 & 0.80 \\
\hline$X 2$ & $\begin{array}{l}\text { TEOS: APTS } 18 \text { : } \\
2\end{array}$ & 297 & 0.32 & 4.4 & 1.81 & 1.13 & 1.54 \\
\hline$X 3$ & $\begin{array}{l}\text { TEOS:TMPD 19: } \\
1\end{array}$ & 516 & 0.48 & 4.4 & 1.96 & 1.26 & 1.55 \\
\hline$X 4$ & $\begin{array}{l}\text { TEOS:TMPD } 18 \text { : } \\
2\end{array}$ & 277 & 0.90 & 12.1 & 3.10 & 2.00 & 2.89 \\
\hline
\end{tabular}

${ }^{a}$ BET specific surface area evaluated in the $0.05-0.25$ range of relative pressures

b Total pore volume $\left(\mathrm{V}_{\mathrm{p}}\right)$ was calculated by converting the amount adsorbed at a relative pressure about 0.99 to the volume of liquid adsorbate

c Average pore size calculated using the BJH method
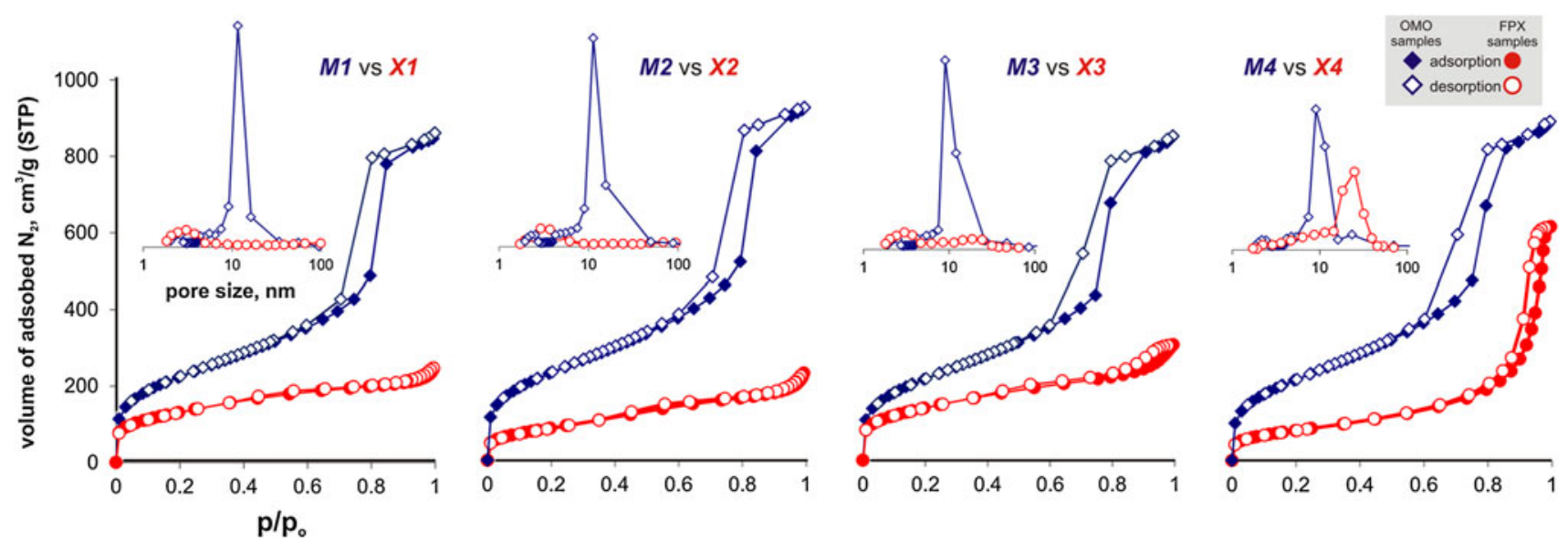

Fig. 2 Nitrogen adsorption/desorption isotherms of the samples studied with corresponding pore size distributions

condensation step, reflecting capillary condensation of adsorbate in the uniform mesopore channels, and evaporation step related to the evacuation of adsorbate from the pores. The isotherms of the samples M1-M4 exhibit hysteresis loops which is attributed to the presence of mesopores in the material. Those loops can be classified as belonging to the type H1 (Rouquerol et al. 1999). Thus, a framework of these materials has a uniform array of mesopores with the same diameter, which is consistent with the XRD and TEM data (vide infra).
Totally different shapes of the isotherms are observed for the APX samples and their attribution to any IUPAC group is ambiguous. The isotherms of samples $X 1$ and $X 2$ exhibit neither capillary condensation, nor hysteresis loop step which means that there are no mesopores, while in the case of $X 3$ a small hysteresis loop can be observed indicating the presence of some mesopores. In the case of the sample $X 4$ a steep increase in the adsorption volume of $\mathrm{N}_{2}$ is observed at $p / p_{\mathrm{o}}$ close to 0.9 . It can be assigned to the presence of intermolecular mesopores between the silica 
nanospheres (Sing et al. 1985). The hysteresis loop of $X 4$ is attributed to the presence of mesopores in the material and is typical of the samples consisting of agglomerates of spheroidal particles of fairly uniform size and array.

The structure-adsorption characteristics are presented in Table 1. The OMO samples have much higher values of the specific surface area $\left(\mathrm{S}_{\mathrm{BET}}\right)$ than corresponding the APX. In the case of OMO, the values of $S_{\mathrm{BET}}$ are in the range $740-840 \mathrm{~m}^{2} / \mathrm{g}$ while in the case of APX$280-520 \mathrm{~m}^{2} / \mathrm{g}$. The sizes of the ordered mesopores of OMO are in the range $6.5-6.8 \mathrm{~nm}$ while for APX $-3.7-12.1 \mathrm{~nm}$. Pore volumes are much higher in the case of the OMO samples $\left(1.29-1.43 \mathrm{~cm}^{3} / \mathrm{g}\right)$ when compared with the corresponding APX samples $\left(0.06-0.48 \mathrm{~cm}^{3} / \mathrm{g}\right)$. Only the sample $X 4$ has a relatively high pore volume $\left(0.90 \mathrm{~cm}^{3}\right)$, not as high as the corresponding $M 4$ sample though $\left(1.30 \mathrm{~cm}^{3}\right)$. The analysis of the values of all parameters confirms deep structural differences between both groups of samples. When comparing the samples within the series, it can be seen that the differences between the values of $S_{\mathrm{BET}}, \mathrm{V}_{\mathrm{p}}$ and $\mathrm{d}_{\mathrm{BJH}}$ are much lower, larger differences are observed for the APX samplesparticularly the sample $X 4$ differs from the remaining APX samples due to the presence of mesopores.

The pore size distributions of all samples are presented as inlets in Fig. 2. For the OMO samples two maxima are present: the first one, a very narrow maximum at $\sim 10 \mathrm{~nm}$ corresponding to the primary ordered mesopores, and the second one located at $\sim 2.5 \mathrm{~nm}$, reflecting the presence of a network of smaller interconnecting pores. For the APX samples $X 1-X 3$ wide pore size distributions are observed with one small maximum at $\sim 3.5-4 \mathrm{~nm}$, while for the $X 4$ sample-at $25, \mathrm{~nm}$ indicating totally different porous structure of the latter sample when compared with the other samples from the APX series.

The XRD patterns (not given here) show typical patterns for both series i.e. ordered and amorphous silicas. In the case of OMO samples three well-resolved peaks are usually observed in the range $2 \theta \approx 0.8-2^{\circ}$. These peaks can be indexed according to the hexagonal p6m symmetry, indicating a SBA-15 mesostructure: one sharp reflection at $2 \theta \approx 0.8$ is indexed as (100) and two minor but distinct reflections at $2 \theta \approx 1.4$ and 1.6, are indexed as (110) and (200), respectively. All three signals disappear gradually with the increasing content of amine groups, which means that the ordering of the samples deteriorates. In the case of APX no signals in the low-angle range are observed demonstrating the lack of any type of ordering and amorphous character of the APX samples.

The SEM micrographs of the samples $M 1, X 1$ and $X 4$ are presented in Fig. 3. All the OMO samples are composed of irregular "needle-like" particles having wormlike structure, i.e. parallelly oriented hexagonal motifs. The
APX samples are composed of aggregated spherical particles. In the case of the sample $X 4$ empty spaces between the aggregates make this sample less compact, when compared to the other samples from the APX series.

\subsection{Sorption studies}

First, the effect of $\mathrm{pH}$ on $\mathrm{Pt}(\mathrm{II})$ adsorption onto the synthesized materials was studied. The series of solutions of the same platinum concentration were prepared and proper initial $\mathrm{pH}\left(\mathrm{pH}_{\mathrm{in}}\right)$ values were set up by adding the hydrochloric acid or sodium hydroxide. Then the $\mathrm{Pt}(\mathrm{II})$ sorption measurements were performed for each solution. In the case of APTS-functionalized samples, the highest adsorption capacity is obtained for the equilibrium $\mathrm{pH}\left(\mathrm{pH}_{\mathrm{eq}}\right)$ of 2.5 and 3.3 for $M 2$ and $X 2$, respectively (Fig. 4). However, the shapes of both curves are different. In the case of sample $M 2$ the changes of the $\mathrm{Pt}(\mathrm{II})$ uptake are strongly pH-dependent, showing a narrow maximum. In contrast, $X 2$ curve exhibits a wide maximum covering the range $\sim 1.8-4.4$. It is worth noting that in the case of sample $M 2$ insignificant differences in $\mathrm{pH}_{\mathrm{eq}}$ are observed for $\mathrm{pH}_{\text {in }}$ between 3.5 and 7 . It means that in this range a buffering effect occurs. For the sample $X 2$ analogus phenomenon is observed for $\mathrm{pH}_{\mathrm{eq}} \approx 5$.

The effect of $\mathrm{pH}$ on $\mathrm{Pt}(\mathrm{II})$ uptake by the TMPD-functionalized samples is shown in Fig. 4. The maximum uptake for $M 4$ is achieved at $\mathrm{pH}_{\mathrm{eq}} \approx 2.5$, and for $\mathrm{X} 4$ the plateau is observed in the range of $\mathrm{pH}_{\mathrm{eq}} \sim 0.8-5.5$ and is slightly $\mathrm{pH}$-dependent for both materials. Outside this range a significant decrease in the adsorbed $\mathrm{Pt}(\mathrm{II})$ species is observed. Similarly to the materials functionalized by APTS, the buffering effect in the range of $\mathrm{pH}_{\mathrm{eq}} \sim 3.5$ for $M 4$ and $\sim 5.5$ for $X 4$, is observed.

The effect of time on adsorption of $\mathrm{Pt}(\mathrm{II})$ ions onto the synthesized materials was studied and is presented in Fig. 5. For the APTS-functionalized samples the rate of the $\mathrm{Pt}(\mathrm{II})$ adsorption is significantly slower for APXs than for OMOs. The adsorption equilibrium for the samples $M 1$ and $M 2$ is achieved after 5 and $10 \mathrm{~h}$, respectively, whereas for the samples $X 1$ and $X 2$ after 72 and $20 \mathrm{~h}$, respectively. For $X 3$ only a $45 \mathrm{~min}$ interval is required for reaching the equilibrium, and $18 \mathrm{~h}$ are necessary for $M 3$. Very slow kinetics for $X 1$ and $X 2$ compared to $M 1$ and $M 2$ (cf. Fig. 5) is probably associated with a considerable content of the amine groups localized in the micropores for APX materials. In the case of OMO samples, the existing micropores follow from the penetration of the silica framework by hydrophilic parts of $\mathrm{P} 123$, thus there should be no considerable number of nitrogen centres located in the micropores. Moreover, in the case of $X 1$ and $X 2$ samples there are no mesopores facilitating the transport of $\mathrm{Pt}(\mathrm{II})$ ions while in the case of all OMO samples mesopores are 

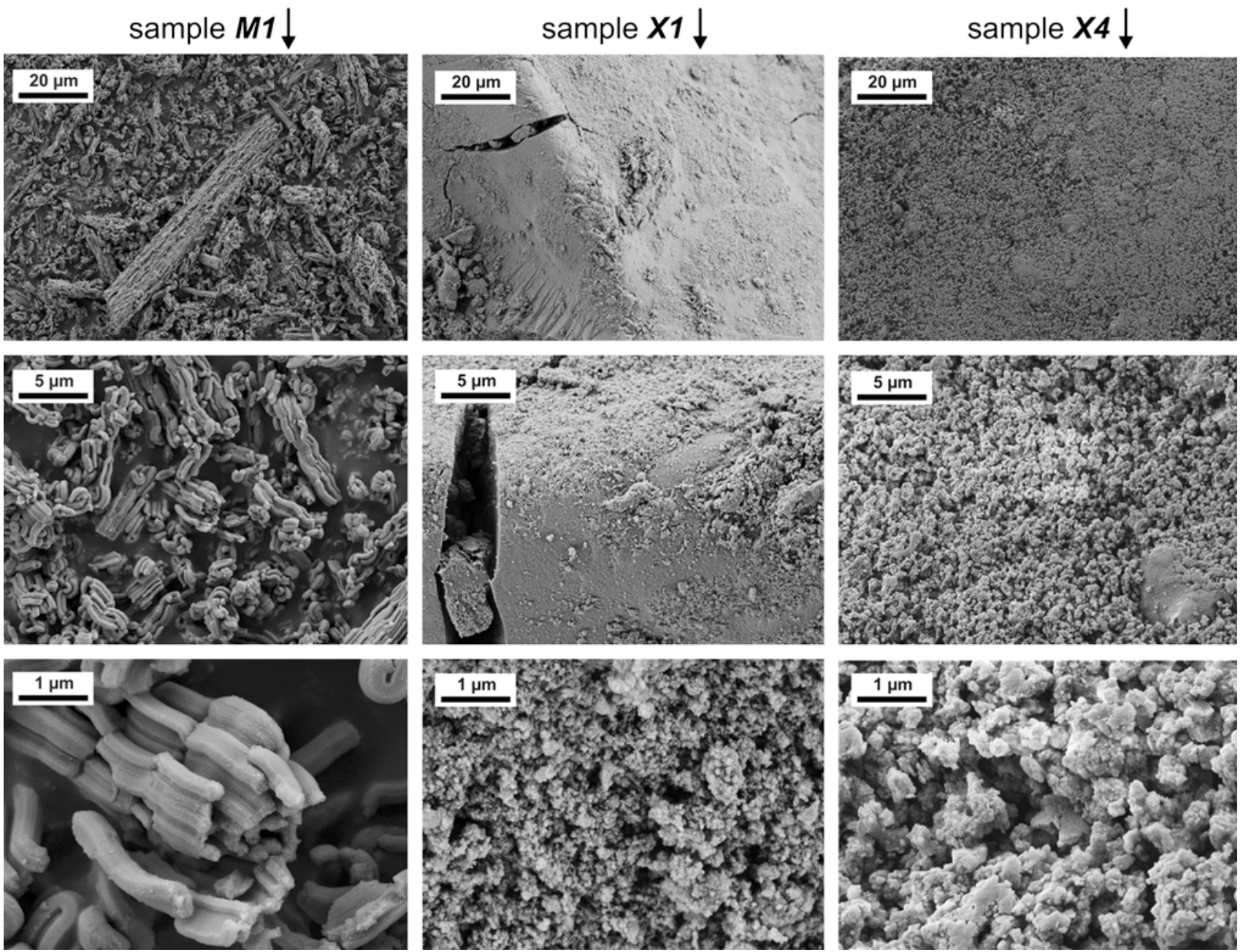

Fig. 3 SEM photographs of the samples $M 1, X 1$, and $X 4$

predominant in the porous structure. As a result, there is a slow transport rate of $\mathrm{Pt}(\mathrm{II})$ ions to the micropores of the adsorbent. In the case of $X 3$ and $X 4$ the amount of mesopores is higher than for $X 1$ and $X 2$ (cf. Fig. 2) Therefore the diffusion into the micropores is facilitated and the adsorption kinetics is much faster. However, despite the relevant mesoporosity in the case of $X 4$ sample as compared with $X 3$, the time needed for reaching equilibrium state is comparable. This suggests that the chemical reactions occurring during the adsorption process are relatively slow constituting the limiting factor for the TMPD-functionalized APX samples.

In order to determine the selectivity of the $\mathrm{Pt}(\mathrm{II})$ sorption from aqueous solutions onto the amine-functionalized silicas, the effect of chloride ions on $\mathrm{Pt}(\mathrm{II})$ adsorption ability was studied in detail. In Fig. 6 the effect of chlorides on the adsorption of $\mathrm{Pt}(\mathrm{II})$ is presented. In the case of $M 2, M 4$ and $X 2$ the presence of chlorides concentration higher than $0.01 \mathrm{~mol} / \mathrm{L}$ causes drastic decrease of the adsorption by about $80-90 \%$. In turn, in the case of $X 4$ the presence of chlorides at the concentration below $0.5 \mathrm{~mol} / \mathrm{L}$ does not cause the decrease of $\mathrm{Pt}(\mathrm{II})$ adsorption. For higher concentrations of chlorides the adsorption of $\mathrm{Pt}(\mathrm{II})$ on $\mathrm{X} 4$ decreases almost proportionally to the chlorides content up to $70 \%$ for $3 \mathrm{~mol} / \mathrm{L}$ chlorides solution. Different behaviour of $X 4$ seems to be the effect of higher adsorption $\mathrm{pH}$ compared to $M 2, M 4$ and $X 2$. The content of amine groups for $X 4$ is the highest comparing with other studied sorbents. Therefore, it appears that $\mathrm{pH}$ in the vicinity of sorbent surface is higher than in the bulk solution and as a result, the hydrolysis of $\mathrm{PtCl}_{4}{ }^{2-}$ complex to more stable aqueous and hydroxy platinum complexes takes place. For the higher $\mathrm{pH}$ value deprotonation of surface amine groups facilitates the adsorption of platinum complexes.

The adsorption ability of APTS-functionalized OMO and APX has been determined by measuring the Pt(II) uptake from its aqueous solutions. The adsorption isotherms are presented in Fig. 7. As it can be noticed for the silicas functionalized by APTS, the adsorbed amount obtained for the OMO samples $M 1$ and $M 2$ is about 1.7 times higher than 

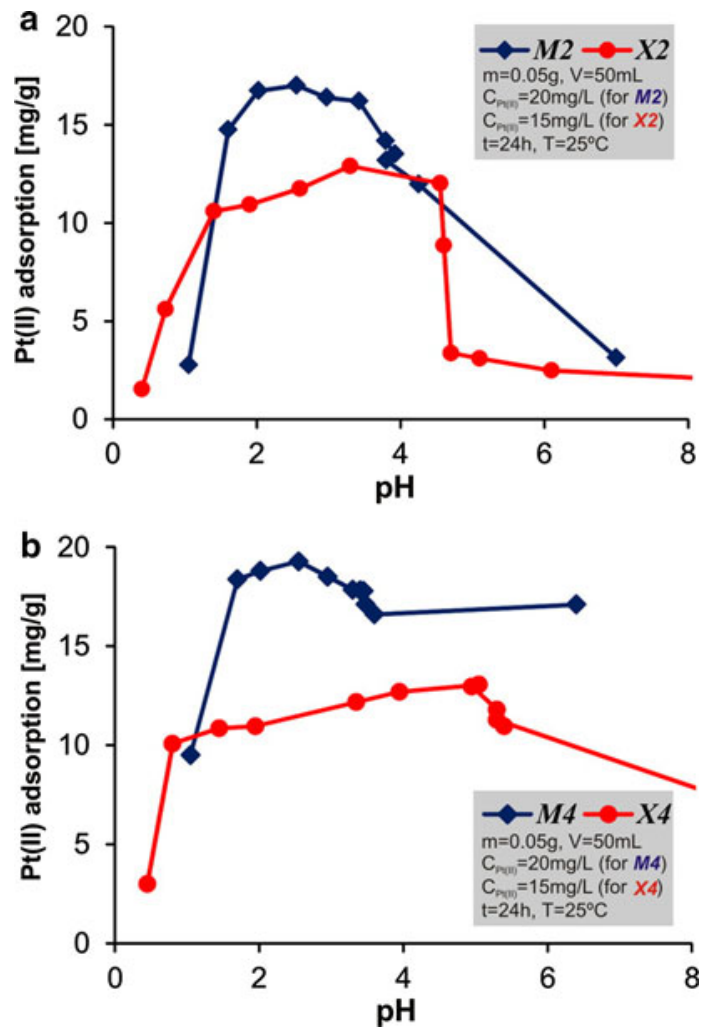

Fig. 4 The $\mathrm{pH}$ influence on $\mathrm{Pt}(\mathrm{II})$ adsorption for the samples $M 2 / X 2$ and $M 4 / X 4$

the corresponding values for the APX samples $X 1$ and $X 2$. However, the amounts of nitrogen in the $X 1$ and $X 2$ samples are significantly higher than for $M 1$ and $M 2$, respectively, which suggests that the adsorption of $\mathrm{Pt}(\mathrm{II})$ ions in the amorphous APTS-functionalized samples is hindered due to limited adsorbate diffusion into the micropores.

For the pure silica samples $M O$ and $X O$ no Pt(II) uptake was observed testifying the fact that the composition of the

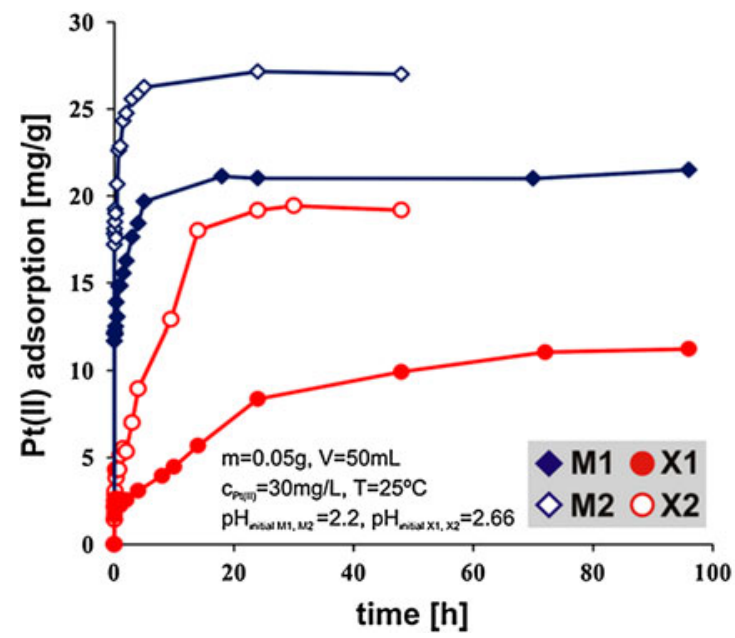

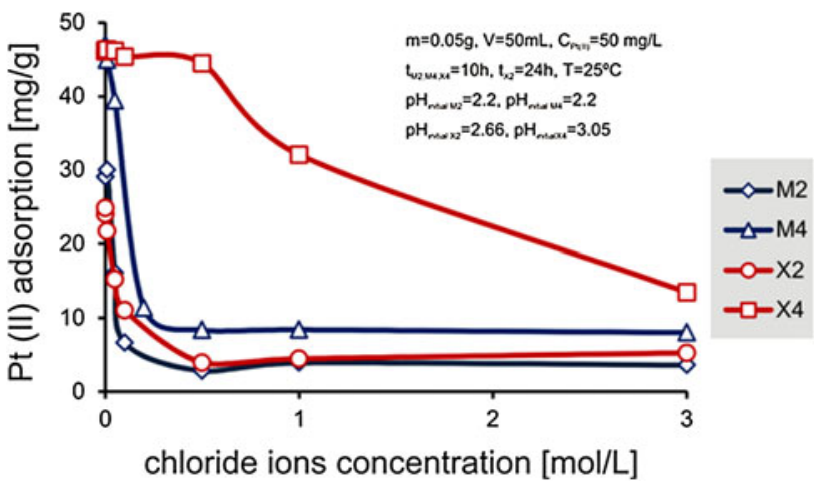

Fig. 6 The influence of chloride ions on Pt(II) adsorption

surface layer is the factor influencing the adsorption properties of the studied systems. The measured values of static sorption capacities (SSC) are 32, 20, 65 and 36 $\mathrm{mg}_{\mathrm{Pt}(\mathrm{II}) / \mathrm{g}}$ for $M 1, X 1, M 2$ and $X 2$, respectively. For the TMPD-functionalized silicas the opposite trend is observed, i.e., higher values of SSC are obtained for the APX than for OMO samples. The measured values of static sorption capacities (SSC) are 50, 87, 102 and $139 \mathrm{mg}_{\mathrm{Pt}(\mathrm{II}) / \mathrm{g}}$ for $M 3, X 3, M 4$ and $X 4$, respectively. Moreover, in the case of the TMPD-functionalized silicas, the adsorption capacities are correlated with the nitrogen content in these sorbents. High SSC values and relatively fast kinetics observed for $X 3$ and $X 4$ suggest that due to the presence of numerous mesopores in the structure of these samples the transport of $\mathrm{Pt}(\mathrm{II})$ ions to the adsorption centres localized in micropores is easier than in the case of the samples $X 1$ and $X 2$. Moreover, a fraction of amine groups is probably inaccessible for $\mathrm{Pt}(\mathrm{II})$ ions in the case of the latter one.

The isotherms presented in Fig. 7 exhibit the Langmuirian behaviour and may be described by the LangmuirFreundlich equation given as:

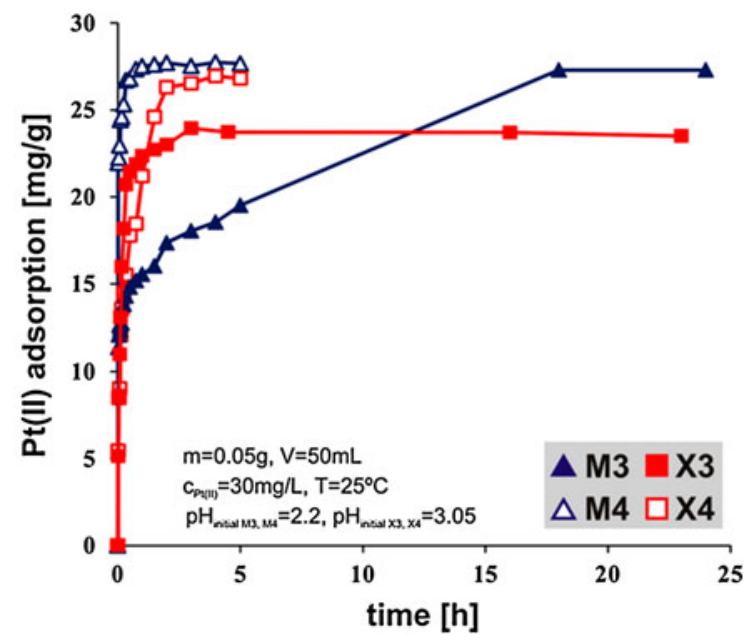

Fig. 5 Adsorption kinetics curves for the samples studied 
$a=a_{m} \frac{(K c)^{n}}{1+(K c)^{n}}$

where, $a$ is the amount of adsorbed platinum at the adsorption equilibrium state $[\mathrm{mg} / \mathrm{g}], a_{m}$ is the maximum adsorption capacity $[\mathrm{mg} / \mathrm{g}], K$ is the Langmuir constant, $c$ is the equilibrium concentration of $\mathrm{Pt}(\mathrm{II})[\mathrm{mg} / \mathrm{L}]$. The parameter $n$ is the factor characterizing the quasi-Guassian energetic heterogeneity of the adsorption system. As the value of this parameter decreases, the energetic heterogeneity of the adsorbent surface increases. In the case when $n \rightarrow 0$ there is high heterogeneity. For $n \rightarrow 1$, equation (1) simplifies to the classical Langmuir adsorption isotherm equation describing the homogeneous adsorbents. On the other hand, in the case of very small equilibrium concentrations, the factor $(\mathrm{Kc})^{\mathrm{n}}$ in equation (1) is much lower than 1 , so that equation (1) reduces to the form:

$a=a_{m}(K c)^{n}$,

which is known as the Freundlich isotherm equation, very often used for explanation of adsorption data because of its simplicity (Jaroniec 1983). The linear form of the Freundlich equation can be expressed as:

$\ln a=\ln \left(a_{m} K\right)+n \ln c$,

where the Langmuir constant $K$ is related to the Freundlich constant $C_{O}$ by the relation:

$\mathrm{K}=\left(\mathrm{C}_{0}\right)^{-\mathrm{n}}$

which, when inserted into equation (3), leads to the following equation:

$\ln a=\ln \left[a_{m}\left(C_{0}\right)^{-n}\right]+n \ln c$

Equation 5 was used to calculate the values of $K, C_{o}, a_{m}$, $n$, and the correlation coefficients $R^{2}$ which are shown in
Table 2. The isotherms presented in Fig. 7 show that the adsorption of $\mathrm{Pt}$ (II) ions satisfies well Eq. 5 (i.e. the Freundlich adsorption isotherm). Comparing the values of parameter $n$ some additional relations can be found. For the ordered silica the decrease in the $n$ values along with the nitrogen content increase is observed. It means that energetic heterogeneity of the functionalized ordered silica increases along with the increase of the nitrogen content. For the disordered functionalized silica, the parameter $n$ shows an opposite tendency, along with the increase of the nitrogen content the increase of the $n$ values can be noted. Energetic heterogeneity decreases along with the increase of the nitrogen content, and for $X 3$ and $X 4$ these materials become energetically homogeneous for the studied adsorption system.

In Table 3 the static sorption capacities of the samples studied here are compared with other studies for $\mathrm{Pt}(\mathrm{II})$ sorption found in the literature (Vassileva et al. 2008; Cox et al. 2005). The materials studied here have a superior properties and the values of static sorption capacity for $\mathrm{Pt}(\mathrm{II})$ ions are the highest when compared with those presented in the former works (Yin et al. 2010; Vassileva et al. 2008; Cox et al. 2005).

In order to explain the mechanism of $\mathrm{Pt}(\mathrm{II})$ ions adsorption onto the amine-functionalized silicas and their chemical behavior on their surfaces, the XPS studies were undertaken. In Fig. 8a the XPS spectrum of the Pt $4 \mathrm{f}$ region for the Pt loaded TMPD-functionalized OMO, being a cut of the full spectrum is shown. For $M 4$ platinum species are characterized by two peaks in the line with the $\mathrm{Pt} 4 \mathrm{f} 7 / 2$ and $\mathrm{Pt} 4 \mathrm{f} 5 / 2$ transitions. This doublet with the peaks (4f $7 / 2$ and $4 \mathrm{f} 5 / 2$ ) at 73.2 and $76.5 \mathrm{eV}$ is assigned to $\mathrm{Pt}(\mathrm{II})$ (Drelinkiewicz et al. 2009). Therefore, the platinum in the second oxidation state is the dominant form of platinum species present on the TMPD-functionalized surface.
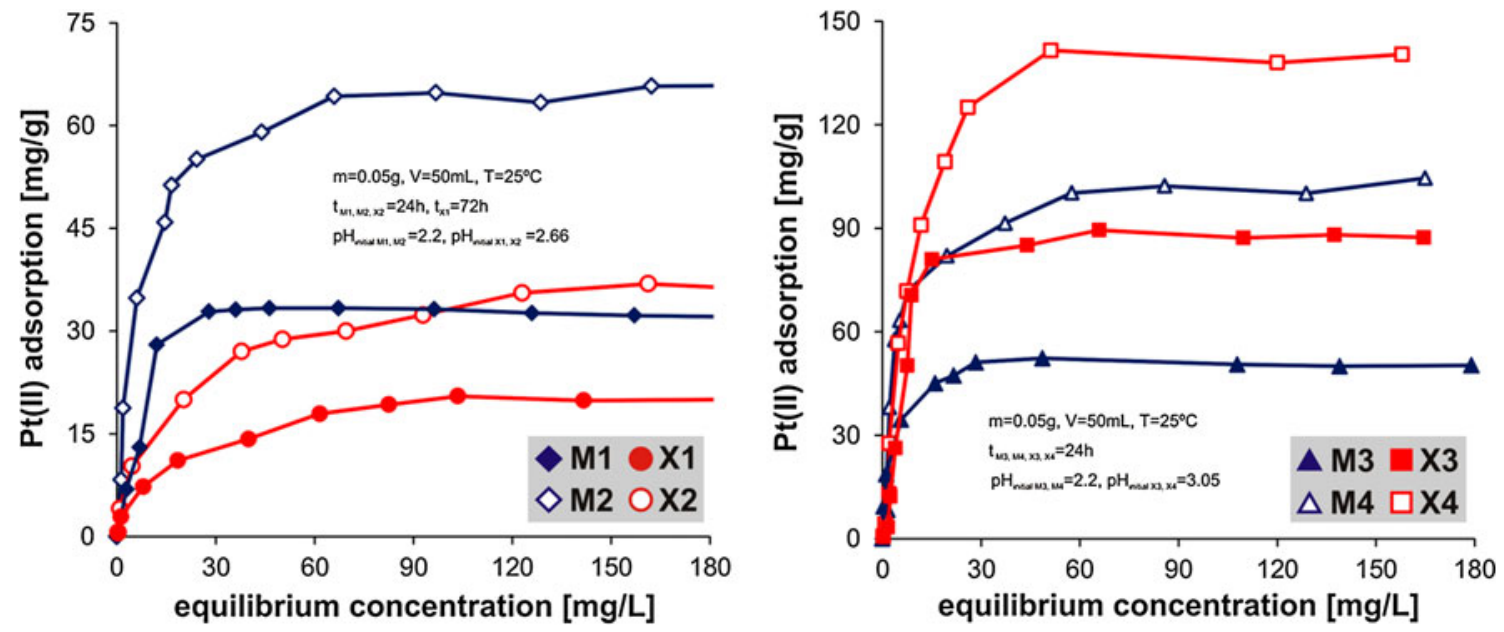

Fig. 7 Adsorption isotherms of Pt(II) for the samples studied 
Table 2 Langmuir-Freundlich parameters for adsorption of $\mathrm{Pt}(\mathrm{II})$ ions on the samples studied

\begin{tabular}{llllcl}
\hline Sample & $a_{m}(\mathrm{mg} / \mathrm{g})$ & $n$ & $K$ & $c_{o}(\mathrm{mg} / \mathrm{L})$ & $R^{2}$ \\
\hline$M 1$ & 32 & 0.73 & 0.09 & 26.48 & 0.923 \\
$X 1$ & 20 & 0.44 & 0.14 & 85.83 & 0.993 \\
$M 2$ & 65 & 0.31 & 0.29 & 59.02 & 0.913 \\
$X 2$ & 36 & 0.42 & 0.14 & 107.36 & 0.974 \\
$M 3$ & 50 & 0.36 & 0.31 & 26.08 & 0.950 \\
$X 3$ & 87 & 1.01 & 0.07 & 13.37 & 0.964 \\
$M 4$ & 102 & 0.20 & 0.52 & 34.43 & 0.957 \\
$X 4$ & 139 & 1.03 & 0.04 & 18.50 & 0.955 \\
\hline
\end{tabular}

Additionally, it was stated that for unloaded M4 the XPS spectra of N1s region are characterized by two peaks at 399.1 and $401.4 \mathrm{eV}$, which corresponds to $-\mathrm{NH}-$ and $-\mathrm{NH}_{2}$ groups (Li et al. 2009). On the other hand, for Pt loaded M4 (Fig. 8b) triplet of N1s is observed with the peaks at 400.1,
401.3 and $402.9 \mathrm{eV}$. The appearance of the third peak with a slight intensity at 402.9 may be explained by oxidation mechanism of $-\mathrm{NH}-$ groups to $-\mathrm{N}^{+}=\mathrm{O}$. It worth to emphasizing that partial transformation of $\mathrm{Pt}(\mathrm{II})$ to $\mathrm{Pt}(\mathrm{IV})$ takes place in the acidic liquid medium (Nischwitz et al. 2003). It means that part of $\mathrm{Pt}(\mathrm{II})$ in a bulk solution could be oxidized to $\mathrm{Pt}(\mathrm{IV})$ during the adsorption process $(24 \mathrm{~h})$. Simultaneously, Pt(IV) ions were reduced to Pt(II) onto the TMPDfunctionalized OMO surface. In the case of Pt loaded APTS-functionalized OMO, the two doublets with the peaks (4f7/2) at 72.5 and 71.4 and (4f5/2) at 75.8 and $74.7 \mathrm{eV}$, respectively, are observed on the XPS spectra of the Pt $4 \mathrm{f}$ region (Fig. 8c). The first pair of peaks corresponds to the $\mathrm{Pt}(\mathrm{II})$ presence, whereas the second doublet proves the presence of metallic Pt. Therefore it is probable that in the case of $M 2$ the partial reduction of $\mathrm{Pt}(\mathrm{II})$ to $\mathrm{Pt}(0)$ takes place. In the case of Pt loaded $M 2$ triplet for N1s region with the peaks at $399.1,400.3$ and $402.2 \mathrm{eV}$ is also observed

Table 3 Comparison of static sorption capacities with regards to $\mathrm{Pt}(\mathrm{II})$ species found in the literature

\begin{tabular}{llll}
\hline Sorbent & $\mathrm{pH}$ & $\mathrm{SSC}(\mathrm{mg} / \mathrm{g})$ & $\mathrm{Ref.}$ \\
\hline Silica gel microspheres encapsulated by imidazole functionalized polystyrene & 5.0 & 68 & (Yin et al. 2010) \\
Thiouracil modified activated carbon & 1.0 & 48 & (Vassileva et al. 2008) \\
Carbon from flax shive & 6.5 & 90 & (Cox et al. 2005) \\
SBA-15 organosilica functionalized with amine groups & 2.2 & 102 & This study \\
Amorphous silica xerogels functionalized with amine groups & 2.2 & 139 & This study \\
\hline
\end{tabular}

a

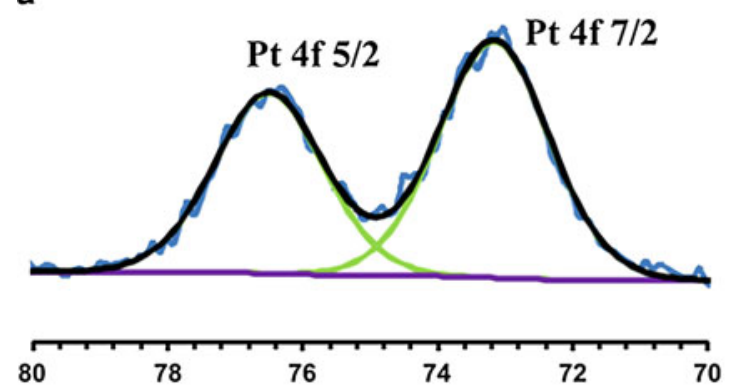

C

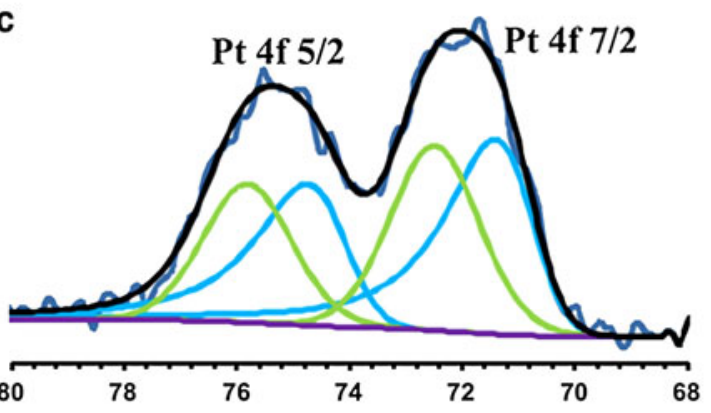

b

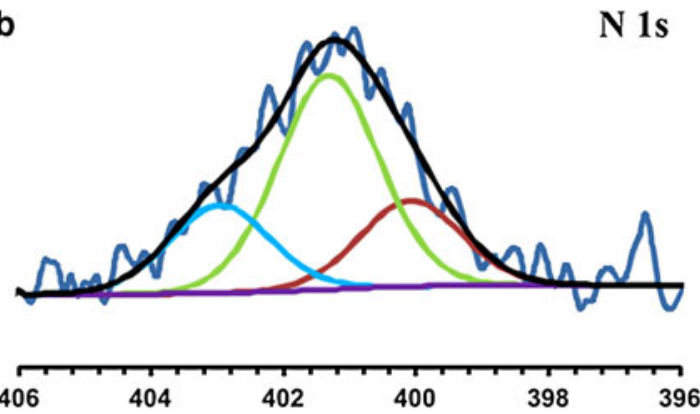

d

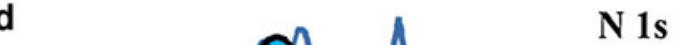

Binding energy (eV)

Fig. 8 XPS spectrum of sample $M 4$ an $M 2$ : a Pt $4 \mathrm{f}$ region of Pt loaded $M 4$, b N 1 s region of Pt loaded $M 4$, $\mathbf{c}$ Pt $4 \mathrm{f}$ region of Pt loaded $M 2$, and d N $1 \mathrm{~s}$ region of Pt loaded M2 
(Fig. 8d). The first two peaks correspond to $-\mathrm{NH}_{2}$ group in the presence of $\left[\mathrm{PtCl}_{4}\right]^{2-}$, forming surface complex. Whereas the peak at $402.2 \mathrm{eV}$ corresponds to the unprotonated $-\mathrm{N}=\mathrm{O}$ group, coming from oxidation of amine groups. The mechanism of $\mathrm{Pt}(\mathrm{II})$ sorption proposed above should be confirmed by another independent method (e.g. Mössbauer spectroscopy) to exclude the influence of X-ray beam on the platinum species during the XPS measurements.
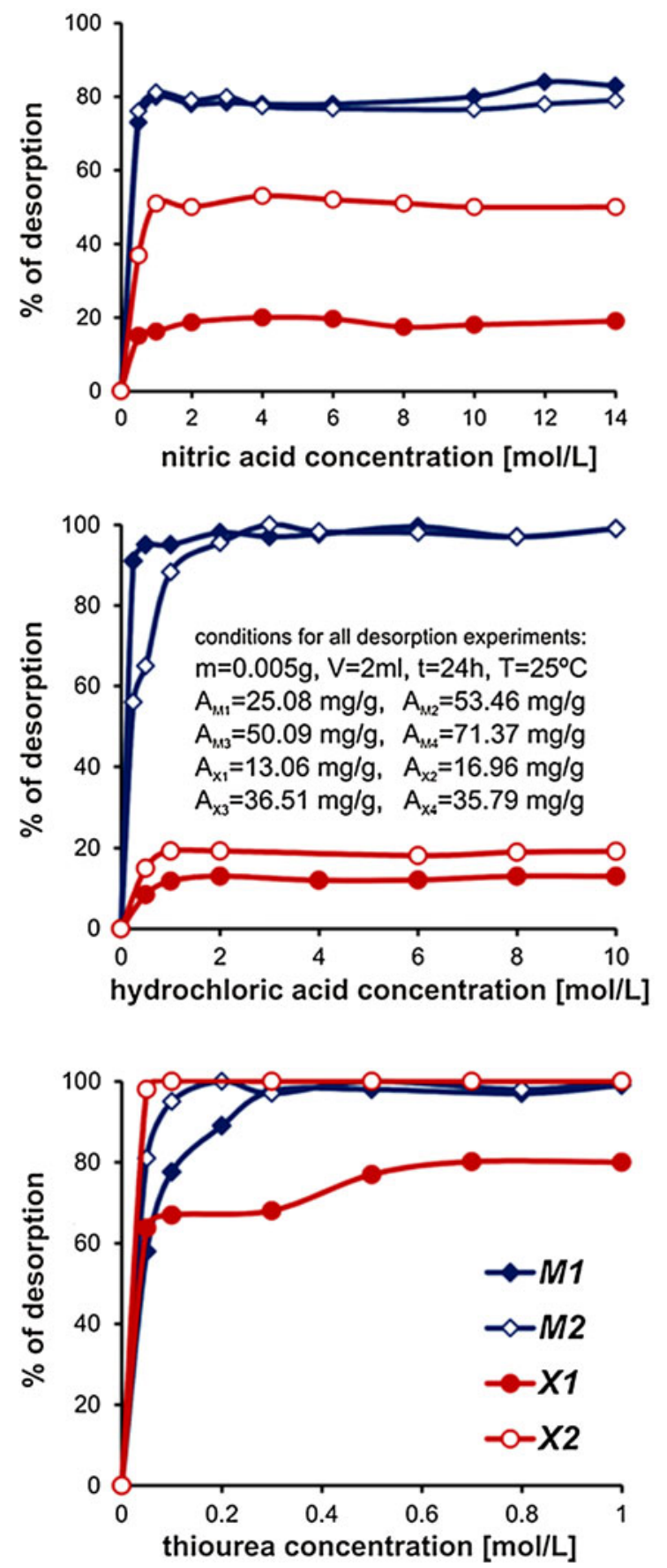

High adsorption capacities of the studied organosilicas create opportunity for their use in the platinum preconcentration and separation from the environmental samples. In order to find how many sorption/desorption cycles can be performed with the prepared sorbents desorption studies were carried out. As the desorption medium $\mathrm{HNO}_{3}, \mathrm{HCl}$ and thiourea in $1.0 \mathrm{~mol} / \mathrm{L} \mathrm{HCl}$ solutions with respect to their concentrations were proposed.
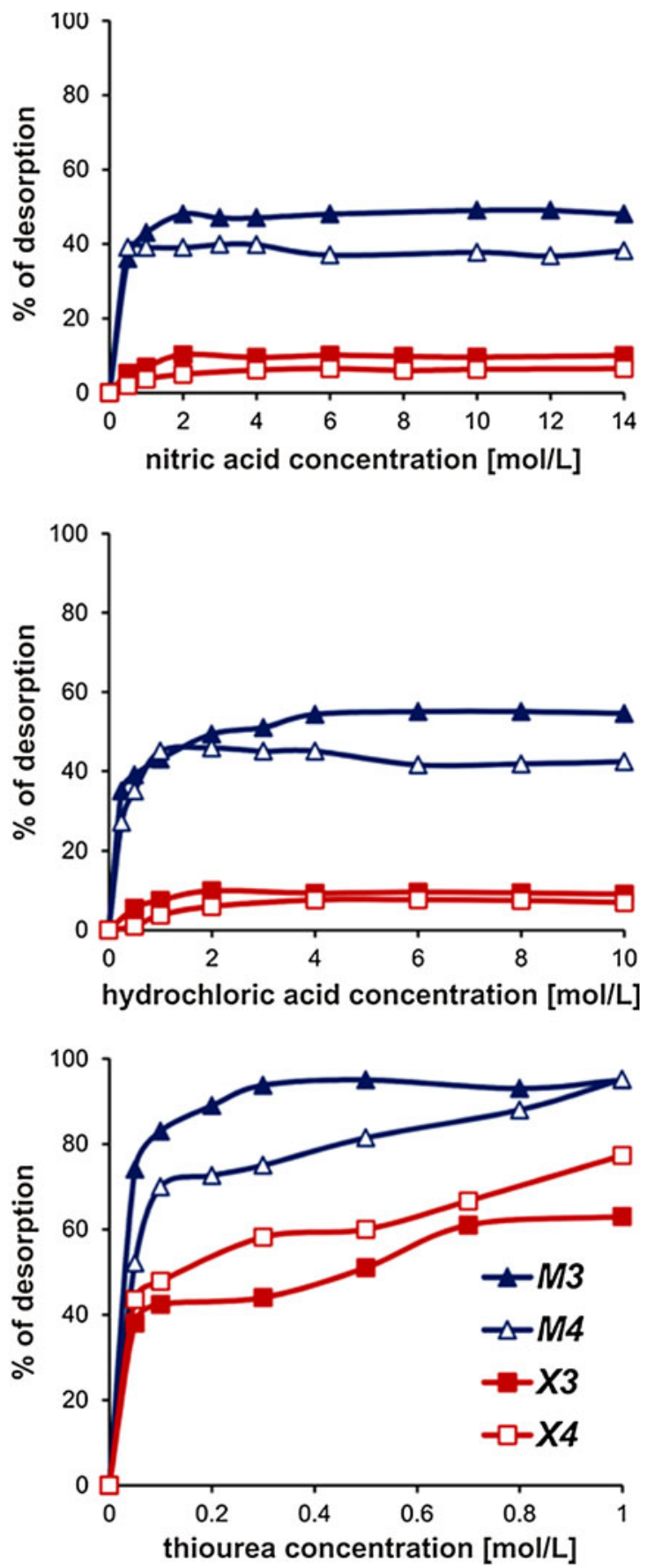

Fig. 9 Desorption of platinum species from the samples $M 1-M 4$ and $X 1-X 4$ by nitric acid, hydrochloric acid and thiourea solutions 
The application of $\mathrm{HNO}_{3}$ as the desorption medium was chosen due to the fact that the nitrate does not form a stable complex with $\mathrm{Pt}(\mathrm{II})$ and $\mathrm{Pt}(\mathrm{IV})$ ions, so its desorption activity is connected only with the competition effect to adsorption centres. In the case of $\mathrm{HCl}$ beyond the competition effect, chlorides can replace $\mathrm{OH}-$ groups in the coordination zone of platinum ions. Whereas thiourea forms a very stable complex with platinum ions so it can compete with $-\mathrm{NH}_{2}$ surface groups.

The desorption study has been presented in Fig. 9. The application of $\mathrm{HNO}_{3}$ causes a partial desorption of platinum species from OMO, whereas for APX especially for $X 3$ and $X 4$ desorption was negligible. In the case of $\mathrm{HCl}$, the application of $2 \mathrm{~mol} / \mathrm{L}$ solution cause the total desorption of platinum species from $M 1$ and $M 2$. While for APX the desorption was lower and does not exceed $10 \%$. When thiourea in $1.0 \mathrm{M} \mathrm{HCl}$ was applied as the desorption medium, the total desorption of platinum species from $M I$, $M 2, M 3, M 4$ and $X 2$ materials was reached. Only for $X 1$, $X 3$ and $X 4$ the platinum species desorption was not quantitative. To summarize, the application of OMOs modified by APTS and TMPD for the Pt(II) ions preconcentration and desorption by thiourea in $1 \mathrm{~mol} / \mathrm{L} \mathrm{HCl}$ creates the possibility of multiple use of sorbents.

\section{Conclusions}

Amorphous polysiloxane xerogels (APX) and ordered mesoporous organosilicas (OMO) functionalized with the amine groups have been synthesized by co-condensation of proper monomers. The OMOs samples have well-ordered porous structure, with the values of specific surface areas in the range $740-840 \mathrm{~m}^{2} / \mathrm{g}$, which are noticeably higher than the corresponding values for the APX samples $\left(280-520 \mathrm{~m}^{2} / \mathrm{g}\right)$. The porous structure for both series of the samples is totally different. Both series of silicas have high contents of amine groups: $0.5-1.3 \mathrm{mmol} / \mathrm{g}$ in the case of $\mathrm{OMO}$ and $0.6-$ $2.0 \mathrm{mmol} / \mathrm{g}$ in the case of APX. This means $70-80 \%$ incorporation efficiency of the amine groups for APX and 50-60\% for the OMO samples was achieved.

Both series contain different fractions of mesopores and micropores which play a crucial role in the case of $\mathrm{Pt}(\mathrm{II})$ adsorption kinetics. The presence of micropores causes slow transport of $\mathrm{Pt}(\mathrm{II})$ ions to the adsorption species and makes a fraction of the amine groups inaccessible to these ions. The adsorption of $\mathrm{Pt}(\mathrm{II})$ ions is strongly $\mathrm{pH}$-dependent and the values of the maximum sorption capacities calculated from the LangmuirFreundlich equation are in the range $32-102 \mathrm{mg}_{\mathrm{Pt}(\mathrm{II}) / \mathrm{g}}$ and 20-139 $\mathrm{mg}_{\mathrm{Pt}(\mathrm{II}) / \mathrm{g}}$ for the OMO and APX series, respectively. Thus the obtained silica adsorbents show strong affinity for $\mathrm{Pt}(\mathrm{II})$, and the proper choice of silica sorbent (e.g. OMO vs. APX) plays a very important role in the case of the $\mathrm{Pt}(\mathrm{II})$ adsorption.

Acknowledgments Mariusz Barczak and Andrzej Dąbrowski acknowledge the Polish Ministry of Science and Higher Education for supporting the research under Grant No. N N204 111135. Dr Piotr Borowski is also acknowledged for his help with the preparation of the manuscript.

Open Access This article is distributed under the terms of the Creative Commons Attribution License which permits any use, distribution, and reproduction in any medium, provided the original author(s) and the source are credited.

\section{References}

Aguado, J., Arsuaga, J.M., Arencibia, A., Lindo, M., Gascon, V.: Aqueous heavy metals removal by adsorption on aminefunctionalized mesoporous silica. J. Hazard. Mat. 163, 213-221 (2009)

Avnir, D., Klein, L.C., Levy, D., Schubert, U., Wójcik, A.B.: Organosilica sol-gel materials. In: Rappoport, Z., Apeloig, Y. (eds.) The Chemistry of Organic Silicon Compounds vol 2, p. 2317. Wiley, New York (1998)

Barczak, M., Pikus, S., Skrzydło-Radomańska, B., Dąbrowski, A.: Synthesis, structure and adsorption properties of nanoporous SBA-15 materials with framework and surface functionalities. Adsorption 15, 278-286 (2009a)

Barczak, M., Borowski, P., Dąbrowski, A.: Structure-adsorption properties of ethylene bridged polysilsesquioxanes functionalized with different groups. Colloids Surf. A 347, 114-120 (2009b)

Barczak, M., Skwarek, E., Janusz, W., Dąbrowski, A., Pikus, S.: Functionalized SBA15 organosilicas as sorbents of zinc(II) ions. Appl. Surf. Sci. 256, 5370-5375 (2010a)

Barczak, M., Dąbrowski, A., Pikus, S., Ryczkowski, J., Borowski, P., Kozak, M.: Studies of the structure and chemistry of SBA-15 organosilicas functionalized with amine, thiol, vinyl and phenyl groups. Adsorption 16, 457-463 (2010b)

Barrett, E.P., Joyner, L.G., Halenda, P.P.: The determination of pore volume and area distributions in porous substances. I. Computations from nitrogen isotherms. J. Am. Chem. Soc. 73, 373-380 (1951)

Beck, J.S., Vartuli, J.C., Roth, W.J., Leonowicz, M.E., Kresge, C.T., Schmitt, K.D., Chu, C.T.-W., Olsen, D.H., Sheppard, E.W., McCullen, S.B., Higgins, J.B., Schlenker, J.L.: A new family of mesoporous molecular sieves prepared with liquid crystal templates. J. Am. Chem. Soc. 114, 10834-10843 (1992)

Bencs, L., Ravindra, K., van Grieken, R.: Methods for the determination of platinum group elements originating from the abrasion of automotive catalytic converters. Spectrochim. Acta B 58, 1723-1755 (2003)

Brinker, C.J., Scherer, G.W.: Sol-gel science. Academic, Nowy Jork (1990)

Brunauer, J.S., Emmet, P.H., Teller, E.: Adsorption of gases in multimolecular layers. J. Am. Chem. Soc. 60, 309-319 (1938)

Bui, T.X., Choi, H.: Adsorptive removal of selected pharmaceuticals by mesoporus silics SBA-15. J. Hazard. Mat. 168, 602-608 (2009)

Cermak, J., Kvicalova, M., Blechta, V., Capka, M., Bastl, Z.: Hydrogenation catalytic activity of substituted cyclopentadienyl titanium complexes anchored on polysiloxanes prepared by a sol-gel procedure. J. Organomet. Chem. 509, 77-84 (1996) 
Colilla, M., Darder, M., Aranda, P., Ruiz-Hitzky, E.: Aminopolysiloxane hybrid materials as carbon composite electrodes for potenciometric detection of anions. J. Mater. Chem. 15, 3844-3851 (2005)

Collinsona, M.M.: Critical sol-gel strategies for the preparation of selective materials for chemical analysis. Rev. Anal. Chem. 29, 289-311 (1999)

Cox, M., Pichuginb, A., El-Shafeyc, E.I., Appletona, Q.: Sorption of precious metals onto chemically prepared carbon from flax shive. Hydrometallurgy 78, 137-144 (2005)

Dąbrowski, A., Barczak, M., Stolyarchuk (Shvaykovska), N.V., Melnyk, I.V., Zub, Y.L.: Bridged polysilsesquioxane xerogels functionalizated by amine- and thiol- groups: synthesis, structure, adsorption properties. Adsorption 11, 501-517 (2005)

Dąbrowski, A., Barczak, M., Dudarko, O.A., Zub, Y.L.: Preparation and characterization of polysiloxane xerogels having covalently attached phosphonic groups. Pol. J. Chem. 81, 475-483 (2007)

Drelinkiewicz, A., Sobczak, J.W., Sobczak, E., Krawczyk, M., Zieba, A., Waksmundzka-Góra, A.: Physicochemical and catalytic properties of Pt-poly(4-vinylpyridine) composites. Mater. Chem. Phys. 114, 763-773 (2009)

El-Nahhal, I.M., El-Ashgar, N.M.: A review on polysiloxaneimmobilized ligand systems; synthesis, characterization and applications. J. Organomet. Chem. 692, 2861 (2007)

El-Nasser, A.A., Parish, R.V.: Solid polysiloxane ligands containing glycine- or iminodiacetate- groups: synthesis and application to binding and separation of metal ions. J. Chem. Soc. Dalton Trans. 19, 3463-3466 (1999)

Feng, X., Fryxell, G.E., Wang, L.-Q., Kim, A.Y., Liu, J., Kemner, K.M.: Functionalized monolayers on ordered mesoporous supports. Science 276, 923-926 (1997)

Ferey, G.: Hybrid porous solids: past, present, future. Chem. Soc. Rev. 37, 191-214 (2008)

Goltner, C.G., Henke, S., Weissenberger, M.C., Antonietti, M.: Mesoporous silica from lyotropic liquid crystal polymer templatesangew. Chem. Int. Ed. 37, 613-616 (1998)

Hartmann, M.: Ordered mesoporous materials for bioadsorption and biocatalysis. Chem. Mater. 17, 4577-4593 (2005)

Humphrey, H.H.P., Botting, C.H., Botting, N.P., Wright, P.A.: Phys. Chem. Chem. Phys. 3, 2983-2985 (2001)

Jaroniec, M.: Physical adsorption on heterogeneous solids. Adv. Coll. Inter. Sci. 18, 149-225 (1983)

Jermakowicz-Bartkowiak, D., Kolarz, B.N., Serwin, A.: Sorption of precious metals from acid solutions by functionalised vinylbenzyl chloride-acrylonitryle-divinylbenzene copolymers bearing amino and guanidine ligands. React. Funct. Polym. 65, 135-142 (2005)

Kang, T., Park, Y., Yi, J.: Highly selective adsorption of $\mathrm{pt}^{2+}$ and $\mathrm{pd}^{2+}$ using thiol-functionalized mesoporous silica. Ind. Eng. Chem. Res. 43, 1478-1484 (2004a)

Kang, T., Park, Y., Choi, K., Lee, J.S., Yi, J.: Ordered mesoporous silica (SBA-15) derivatized with imidazole-containing functionalizes as a selective adsorbent of precious metal ions. J. Mater. Chem. 14, 1043-1049 (2004b)

Kickelbick, G.: Introduction to hybrid materials. In: Kickelbick, G. (ed.) Hybrid Materials. Wiley-VCH Verlag GmbH \& Co. KGaA, Weinhem (2007)

Kresge, C.T., Leonowicz, M.E., Roth, W.J., Vartuli, J.C., Beck, J.S.: Ordered mesoporous molecular sieves synthesized by a liquidcrystal template mechanism. Nature 359, 710-712 (1992)

Li, X.G., Ma, X.L., Sun, J., Huang, M.R.: Powerful reactive sorption of silver(I) and mercury(II) onto poly(o-phenylenediamine) microparticles. Langmuir 25, 1675-1684 (2009)

Liu, A.M., Hidajat, K., Kawi, S., Zhao, D.Y.: A new class of hybrid mesoporous materials with functionalized organic monolayers for selective adsorption of heavy metal ions. Chem. Commun. 13, 1145-1146 (2000)

Loy, D.A., Jamison, G.M., Baugher, B.M., Myers, S.A., Assink, R.A., Shea, K.J.: Sol-gel synthesis of hybrid organic-inorganic materials. hexylene- and phenylene-bridged polysiloxanes. Chem. Mater. 8, 656-663 (1996)

Nischwitz, V., Michalke, B., Kettrup, A.: Speciation of Pt(II) and $\mathrm{Pt}(\mathrm{IV})$ in spiked extracts from road dust using on-line liquid chromatography-inductively coupled plasma mass spectrometry. J. Chromatogr. A 1016, 223-234 (2003)

Olkhovyk, O., Jaroniec, M.: Ordered mesoporous silicas with 2,5dimercapto-1,3,4-thiadiazole ligand: high capacity adsorbents for mercury ions. Adsorption 11, 205-214 (2005)

Rouquerol, F., Rouquerol, J., Sing, K.: Adsorption by Powders and Porous Solids. Principles, Methodology and Application, pp. 18-20. Academic Press, London (1999)

Sakka, S. (ed.): Handbook of Sol-Gel Science and Technology: Processing, Characterization, and Applications. Kluwer, Dordrecht (2005)

Shea, K.J., Moreau, J., Loy, D.A., Corriu, R.J.P., Boury, B.: Bridged polysilsesquioxanes. Molecular-engineering nanostructured hybrid organic-inorganic materials. In: Gomez-Romero, P., Sanchez, C. (eds.) Functional Hybrid Materials, pp. 50-85. Wiley-VCH, Weinheim (2004)

Sing, K.S., Everett, D.H., Haul, R.A.W., Moscou, L., Pierotti, R.A., Rouquerol, J., Siemieniewska, T.: Reporting physisorption data for gas/solid systems with special reference to the determination of surface area and porosity. Pure Appl. Chem. 57, 603-619 (1985)

Slinyakova, I.B., Denisova, T.I.: Kremniiorganicheskie adsorbenty. Poluchenie, svoistva, primenenie (Organosilicon Adsorbents: Synthesis, Properties, Applications). Naukova Dumka, Kiev (1988)

Taguchi, A., Schüth, F.: Ordered mesoporous materials in catalysis. Microporous Mesoporous Mater. 77, 1-45 (2005)

Trewyn, B.G., Giri, S., Slowing, I.I., Lin, V.S.-Y.: Mesoporous silica nanoparticle based controlled release, drug delivery, and biosensor systems. Chem. Commun. 31, 3236-3245 (2007)

Vassileva, P., Tzvetkova, P., Lakov, L., Peshev, O.: Thiouracil modified activated carbon as a sorbent for some precious and heavy metal ions. J. Porous Mater. 15, 593-599 (2008)

Yanagisawa, T., Shimizu, T., Kuroda, K., Kato, C.: The preparation of alkyltrimethylammonium-kanemite complexes and their conversion to microporous materials. Bull. Chem. Soc. Jpn. 63, 988-992 (1990)

Yin, P., Xu, Q., Qu, R., Zhao, G., Sun, Y.: Adsorption of transition metal ions from aqueous solutions onto a novel silica gel matrix inorganic-organic composite material. J. Hazard. Mater. 173, $710-716(2010)$

Zhao, D.Y., Feng, J.L., Huo, Q.S., Melosh, N., Fredrickson, G.H., Chmelka, B.F., Stucky, G.D.: Triblock copolymer syntheses of mesoporous silica with periodic 50 to 300 angstrom pores. Science 279, 548-552 (1998a)

Zhao, D.Y., Huo, Q.S., Feng, J.L., Chmelka, B.F., Stucky, G.D.: Nonionic triblock and star diblock copolymer and oligomeric surfactant syntheses of highly ordered, hydrothermally stable, mesoporous silica structures. J. Am. Chem. Soc. 120, 6024-6036 (1998b)

Zolotov, Y.A., Kuzmin, N.M.: Preconcentration of Trace Elements. Elsevier, Amsterdam (1990)

Zub, Y.L., Stolyarchuk, N.V., Barczak, M., Dąbrowski, A.: Surface heterogeneity of polysiloxane xerogels functionalized by 3 -aminopropyl groups. Appl. Surf. Sci. 256, 5361-5364 (2010) 